\title{
A rheological description of the water vapour sorption kinetics behaviour of wood invoking a model using a canonical assembly of Kelvin-Voigt elements and a possible link with sorption hysteresis
}

\author{
Callum A.S. Hill ${ }^{1} *$, Barbara A. Keating ${ }^{1}$, Zaihan \\ Jalaludin $^{1,2}$ and Eike Mahrdt ${ }^{3}$ \\ ${ }^{1}$ Forest Products Research Institute, Joint Research \\ Institute for Civil and Environmental Engineering, \\ Edinburgh Napier University, Edinburgh, EH10 5DT, UK \\ ${ }^{2}$ Forest Research Institute Malaysia, 52109 Kepong, \\ Selangor DE, Malaysia \\ ${ }^{3}$ University of Göttingen, Wood Biology and Wood \\ Products, Büsgenweg 4, 37077 Göttingen, Germany \\ * Corresponding author. \\ Forest Products Research Institute, Joint Research Institute for \\ Civil and Environmental Engineering, Edinburgh Napier \\ University, Edinburgh, EH10 5DT, UK \\ Phone: +44 1314552336 \\ E-mail: c.hill@ napier.ac.uk
}

\begin{abstract}
The dynamic vapour sorption behaviour of two Malaysian hardwoods, acacia (Acacia mangium Wild) and sesendok (Endospermum malaccense Bent ex Müll. Arg.) was studied over a narrow temperature range $\left(20-40^{\circ} \mathrm{C}\right)$. The rate of sorption or desorption of water into or out of the wood cell wall was considered to be limited by the viscoelastic behaviour of the material and the sorption kinetics was accordingly analysed in terms of a canonical series of Kelvin-Voigt elements. A two series and three series model have been applied to the kinetic data and the results are compared. Characteristic times and moisture contents were obtained from the models. The Arrhenius equation was used in conjunction with the reciprocals of the characteristic times to calculate the activation energy and activation entropy of sorption, and the Gibbs free energy of activation for the sorption process was also determined. This is the first time that entropy of activation and Gibbs free energy of activation for sorption processes with wood have been reported. Interpretation of these data invokes a model describing the polymeric relaxation processes occurring within the cell wall during adsorption or desorption. A possible link between sorption kinetics, polymeric relaxation processes, and sorption hysteresis is discussed.
\end{abstract}

Keywords: activation energy; activation entropy; cell wall; dynamic vapour sorption; Kelvin-Voigt model; kinetics Gibbs free energy of activation; viscoelasticity; water vapour; wood.

\begin{abstract}
Introduction
The scientific discussion concerning the interrelation of wood with moisture has a long tradition, but it is still frequently a topic in the context of thermal modification (Pfriem et al. 2010), chemical modification (Dieste et al. 2008), damaged wood (Todoruk and Hartley 2011), or wood drying (Herritsch and Nijdam 2009), just to mention a few. There are still open questions in terms of theoretical backgrounds and reliable measurements.
\end{abstract}

\section{Basic theoretical considerations}

It is well known that wood responds to variations in atmospheric relative humidity $(\mathrm{RH})$ with changes in cell wall moisture content (MC) and volume. A wood sample exposed to a constant $\mathrm{RH}$ will eventually attain a stable equilibrium moisture content (EMC). Plots of EMC against RH at constant temperature are known as sorption isotherms. Sorption isotherms of wood are characterised by their sigmoidal shape and the phenomenon of hysteresis between the adsorption and desorption branches of the isotherm (Siau 1984; Skaar 1988). The literature abounds with studies on sorption isotherms (e.g., Venkateswaram 1970; Simpson 1980) and there have also been many reports on the sorption kinetic behaviour of wood, although the practical determination of truly accurate kinetic curves requires skilled experimental work. These sorption kinetics studies invariably interpret the data in terms of a Fickian model (e.g., Droin et al. 1988; Wadsö 1994a,b; Houska and Koc 2000; Time 2002; Krabbenhoft and Damkilde 2004; Shi 2007; Salin 2010). Such models may be valid when considering large wood specimens, but this is not the case when considering small sample sizes (Wadsö 1994a,b). It has been demonstrated that non-Fickian diffusion is observed when the water vapour sorption kinetics of thin wood and cellulosic samples is examined and that the sorption kinetics is related to the swelling of the substrate (Christensen 1959, 1965). Krabbenhoft and Damkilde (2004) were able to show the non-Fickian nature of the sorption process by studying thin samples of wood of variable length, and developed a model based upon the premise that sorption behaviour was limited by the rate of swelling of the substrate. The relatively recent availability of dynamic sorption equipment, with the ability to measure mass change in "real time" offers exciting opportunities for re-evaluating historical assumptions. Our research group has been studying the sorption kinetics properties of cellulose, plant fibres and 
wood samples by means of such modern apparatus for over five years and it has been found that this behaviour (at least with small wood, plant fibre, or cellulosic samples weighing $<100 \mathrm{mg}$ ) is definitely non-Fickian and that extremely accurate and reproducible fits to the data are obtained based on the model called parallel exponential kinetics (PEK) (Hill et al. 2010a,b,c, 2011; Jalaludin et al. 2010a,b,c; Sharratt et al. 2010; Xie et al. 2010a,b, 2011a,b; Hill and Xie 2011a). This clearly requires that wood sorption behaviour is re-appraised.

It is well established that the diffusion behaviour of swelling polymers cannot be described by Fickian models, particularly in the case of glassy polymeric materials (Alfrey et al. 1966; Crank 1998). The PEK model is applicable to a relaxation-limited diffusion situation, where the rate of diffusion is very fast compared to the rate of relaxation. The PEK equation has the form:

$M C=M C_{1}\left[1-\exp \left(-t / t_{1}\right)\right]+M C_{2}\left[1-\exp \left(-t / t_{2}\right)\right]$

where $\mathrm{MC}$ is the moisture content at time $t, M C_{1}$ and $M C_{2}$ are moisture contents at infinite time and $t_{1}, t_{2}$ are characteristic times for the two kinetic processes. The behaviour is represented by a fast and a slow sorption process taking place simultaneously. The PEK model is also applicable to natural fibres (Kohler et al. 2003; Hill et al. 2010c), regenerated cellulosic fibres (Okubayashi et al. 2004, 2005a,b), microcrystalline cellulose (Kachrimanis et al. 2006) and foodstuffs (Madamba et al. 1996; Rahman et al. 1998).

At present, there is no consensus regarding the physical interpretation of the PEK model. The MC associated with the fast kinetic process has been proposed to be related to moisture sorption at the sites of the readily accessible internal surfaces and "amorphous" regions, whilst the slow kinetic process has been attributed to sorption onto the "inner'" surfaces and "crystallites"' (Okubayashi et al. 2004). Alternatively, it has been suggested that the fast process is associated with the formation of monolayer, or "bound" water within the cell wall, with the slow process assigned to multilayer or "free" water within the cell wall (Kohler et al. 2003). These hypotheses have been tested and discussed recently and it is concluded that there is little evidence supporting the idea of assigning the two processes to specific sites or water types (Hill et al. 2010a,b,c; Xie et al. 2010a,b, 2011a,b). It is known that the swelling behaviour of cereal grains obeys a PEK model (Tang et al. 2008), which can be interpreted that the sorption rate is limited by the ability of the cell wall matrix to deform in response to the ingress or egress of water molecules.

In the PEK model, the sorption kinetics is separated into two first order kinetic processes, with the reciprocals of the characteristic times of the fast and slow processes giving the corresponding rate constants for those processes $\left(k_{1}=1 / t_{1}\right.$, $\left.k_{2}=1 / t_{2}\right)$. Higher order models have correspondingly more constants $\left(k_{i}=1 / t_{i}\right)$. From the rate constants, it is then possible to determine the activation energies associated with the rate determining step of these sorption processes by using the Arrhenius relationship:
$k=A \cdot \exp (-E a / R T)$

where $k$ is the rate constant, $A$ is the collision factor, $R$ the gas constant, $T$ the absolute temperature and $E a$ is the activation energy. By taking natural logarithms of both sides, the equation becomes:

$\ln (k)=\ln (\mathrm{A})-E a / R T$

Thus, a plot of $\ln (k)$ vs. the reciprocal absolute temperature will yield a straight line of gradient $-E a / R$, if the Arrhenius relationship is obeyed. Multiplying the gradient of the slope by $R\left(8.314 \mathrm{~J} \mathrm{~K}^{-1} \mathrm{~mol}^{-1}\right)$ yields the activation energy.

Two previous papers have reported upon determination of the activation energies of sorption for Sitka spruce (Picea sitchensis) (Hill et al. 2010a) and for flax (Linum usitatissimum) (Hill et al. 2010c). But the Arrhenius relationship is also suitable for determination of the activation entropy. The intercept $\ln (A)$ at infinite temperature $(1 / T=0)$ is related to the activation entropy $(\mathrm{Sa})$ by the following relationship (Glasstone and Lewis 1960; Hill and Papadopoulos 2002):

$A=(e R T / n h) \cdot \exp (\Delta S a / R)$

where $n$ is Avagadro's number, $h$ is the Planck constant and $e$ is the mathematical constant. It should be noted that the time units can be chosen arbitrarily for calculating the activation energy, but for determination of the activation entropy, it is essential to use reciprocal seconds for the rate constants. Finally, the Gibbs free energy of activation $(G a)$ can be calculated by applying the following formula (Low et al. 1973):

$\Delta G a=E a-R T-T . \Delta S a$

\section{Interpretation of sorption kinetics in terms of viscoelasticity}

When water vapour is adsorbed onto the internal surface of wood cell walls, the sorbed water molecules exert an internal pressure within the inter-microfibrillar elastic gel matrix. The volume change of this matrix material is a balance of the swelling pressure exerted by the adsorbed water molecules and the resistance to that swelling pressure provided by the matrix. This determines the equilibrium moisture content (EMC) under conditions of equilibrium, but prior to this state being realised, the material is in a dynamic state and the water sorption behaviour is subject to kinetic considerations.

Assuming that the rate of water sorption in the cell wall is limited by the mechanical response of the material, then an appropriate model is one, where there are a number of Kelvin-Voigt viscoelastic elements (K-V elements) arranged in series (Figure 1) (Passard and Perre 2005). Such canonical models are often used in studies of polymer relaxation (Barnes et al. 1989). The PEK model can be viewed as a simplified case of what could be a potentially infinite assembly of series-coupled K-V elements that could describe the moisture sorption kinetics of the cell wall of wood, plant 


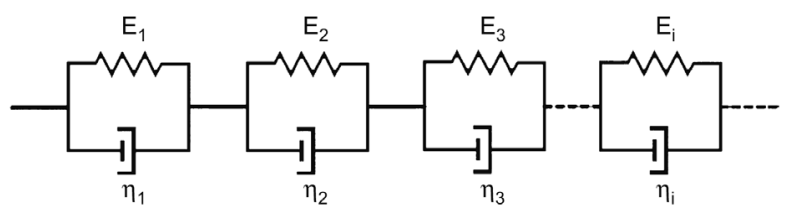

Figure 1 A series of Kelvin-Voigt viscoelastic elements.

fibres, and other natural materials. The form of the fast and slow component of the PEK equation is identical with that describing the dynamic response of a $\mathrm{K}-\mathrm{V}$ element when subjected to an instantaneous stress increase $\left(\sigma_{O}\right)$ :

$\varepsilon=\left(\sigma_{0} / E\right)[1-\exp (-\mathrm{t} / \varphi)]$

where $\varepsilon$ is the strain at time $t, E$ is the elastic modulus and $\varphi$ is a time constant which is defined as the ratio $\eta / E$, where $\eta$ is the viscosity (Barnes et al. 1989).

In the present case, there is a change in atmospheric relative humidity $(\mathrm{RH})$, which leads to a response in the wood cell wall. The maximum swelling pressure $(\Pi$-which is here equivalent to $\sigma_{0}$ )-that is exerted on an elastic gel when the surrounding water vapour pressure is raised from an initial value $p_{i}$ to final value $p_{f}$-is given by the following equation (Krabbenhoft and Damkilde 2004):

$$
\Pi=-(\rho / \mathrm{M}) \mathrm{RT} \cdot \ln \left(p_{i} / p_{f}\right)
$$

where $\rho$ is the density and $M$ is the molecular weight of water, $R$ is the gas constant and $T$ is the isotherm temperature in Kelvin.

In the present situation, the strain of the system is assumed to be equivalent to the volume change of the cell wall as a result of water vapour adsorption or desorption. This volume change is assumed to be linearly related to the change in the mass fraction of the water present in the cell wall.

The adsorbed water vapour molecules exert a pressure within the cell wall leading to dimensional change, which is equivalent to the extension of the spring in the Kelvin-Voigt model. This expansion/extension results in an increase in the free energy of the system (Matsuoka 1992). Expansion will continue until the free energy of the system is equal to the free energy of the water vapour molecules in the atmosphere. The spring modulus therefore defines the water content of the system at infinite time $\left(M C_{1}, M C_{2}\right)$.

$M C_{1}=\sigma_{0} / E_{1 ;} M C_{2}=\sigma_{0} / E_{2 ; \ldots \ldots . . M C_{i}}=\sigma_{0} / E_{i}$

The rate, at which water molecules are adsorbed or desorbed by the system, is a function of the viscosity of the dashpot in the model. This viscosity is, in turn, related to the micro-Brownian motion of the cell wall macromolecular network. The more rapidly the matrix is able to deform, the faster the rate of water ingress or egress into or out of the cell wall. The rate of local deformation is related to the energy barrier associated with the local relaxation process and whether there is sufficient free volume to allow the relaxation process to take place. In glassy solids below the glass tran- sition temperature $(\mathrm{Tg})$ there is insufficient free volume to allow a local relaxation to take place without the cooperative motion of adjacent relaxors (a relaxor is defined as the smallest molecular segment of relaxation in each polymeric unit). This gives rise to the concept of cooperative domains within the matrix (Matsuoka 1992; Matsuoka and Hale 1997; Bartolotta et al. 2010). As the glass transition temperature is approached, the domain size decreases until $T g$ is reached. At this point, the domain contains only one relaxor and there is sufficient free volume to allow for relaxation without the cooperation of neighbours.

\section{Objectives}

One purpose of this paper is to examine the consequences of introducing additional $\mathrm{K}-\mathrm{V}$ elements to the rheological model describing water vapour sorption kinetics. The first section looks at the consequence of including two, three, four and five $\mathrm{K}-\mathrm{V}$ elements upon the accuracy of fit to the data. The paper then goes on to examine the activation energies, entropies and Gibbs free energies of sorption throughout the hygroscopic range based on a PEK interpretation of the kinetic data and the consequence of introducing one further term (herein termed a triple exponential kinetics "TEK" model).

The study reported herein represents part of a comprehensive investigation into the behaviour of water vapour sorption kinetics of wood and plant-derived materials. The objectives were to make further determinations of the activation energy of sorption with other wood species, as well as to evaluate activation entropies and Gibbs free energy of sorption, which has not previously been reported upon. The paper also examines the mechanical interpretation of the sorption kinetics based on the Kelvin-Voigt viscoelastic model and explores the possibility of a link between sorption hysteresis and kinetic behaviour.

\section{Materials and methods}

Instrument for isotherm analyses: Dynamic Vapour Sorption Intrinsic apparatus (Surface Measurement Systems Ltd., London, UK). The DVS instrument comprises a measurement pan suspended from a Cahn ultra-sensitive microbalance that is capable of measuring changes in sample mass to a resolution of 1 part in 10 million. The wood samples (heartwood only) were studied in the form of a wood flour obtained from kiln-dried wood which was ground in a Wiley mill and passed through a BS410-1:2000 sieve no. $20(0.841 \mathrm{~mm}$ sieve opening) (Jalaludin et al. 2010c). The test material (5 $\pm 1 \mathrm{mg}$ ) was placed onto a cleaned sample pan which was carefully hooked onto the hang down wire connected to the microbalance in a climate controlled chamber (located in a thermostatically controlled cabinet) through which there was a constant flow of dry nitrogen gas and into which was mixed another flow of nitrogen containing water vapour. The sample mass readings from the microbalance then reveal the vapour adsorption/desorption behaviour of the material. The schedule for the DVS was set to 20 different RHs $(0,5,10$, $15,20,25,30,35,40,45,50,55,60,65,70,75,80,85,90$ and $95 \%$ and at five temperatures of $20,25,30,35$ and $38^{\circ} \mathrm{C}$ and in the reverse sequence for the desorption isotherm). The instrument maintained the sample at a constant $\mathrm{RH}$ until the rate change in mass 

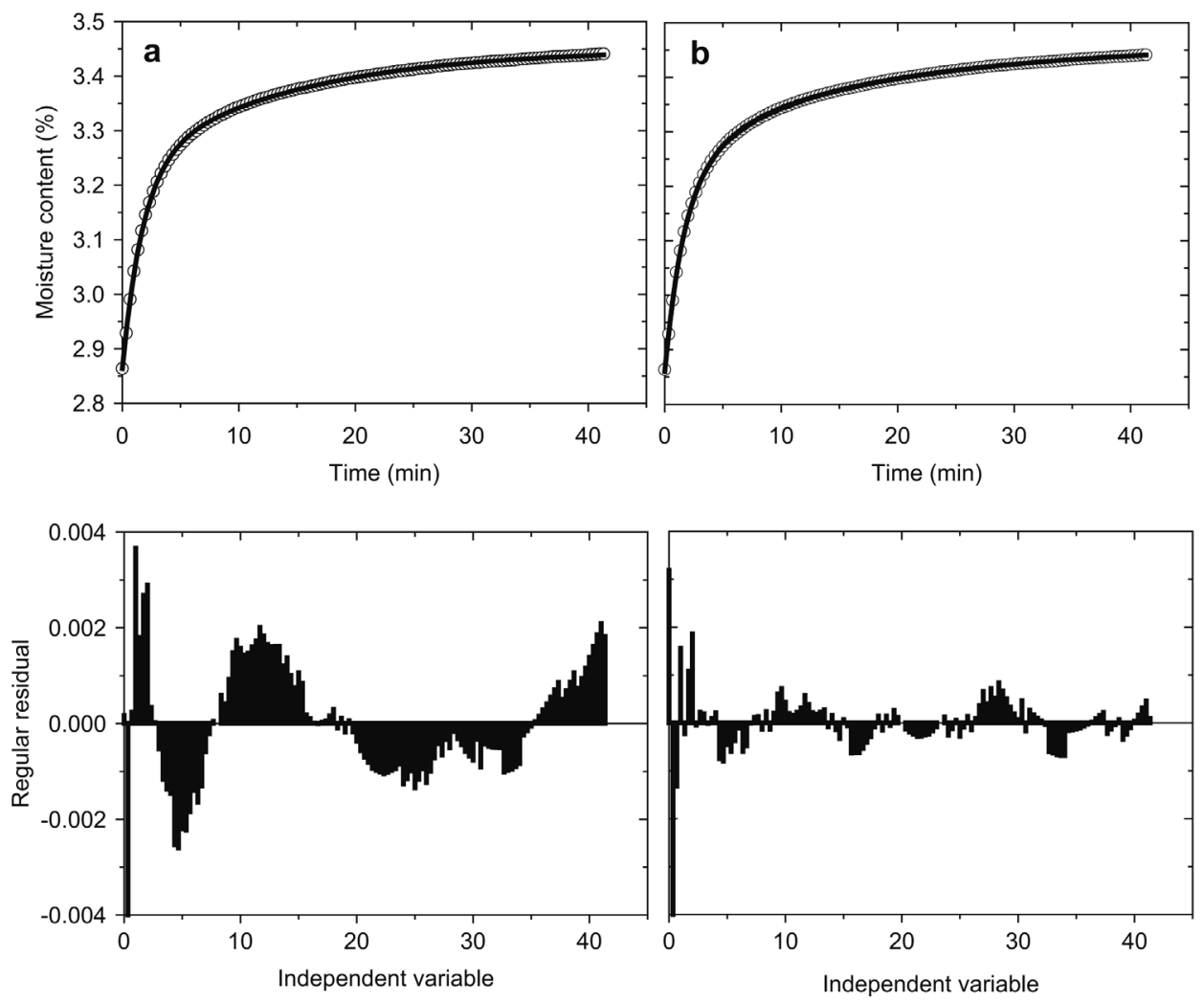

Figure 2 Example curve fits showing a PEK curve fit (a) with the residuals below and a TEK curve fit (b) with associated residuals.

$(\mathrm{dm} / \mathrm{dt})$ was $<0.002 \% \mathrm{~min}^{-1}$ over a $10 \mathrm{~min}$ period, a criterion that from previous experiment had been shown to give a sample MC to within $<0.1 \%$ of the equilibrium value (Hill et al. 2010a). Data on mass change was acquired every $20 \mathrm{~s}$. Each kinetic curve was obtained by plotting percentage mass gain/loss against time, with time zero corresponding to the point, at which a $\mathrm{RH}$ step change occurs. However, a change of RH from $0 \%$ to $5 \%$ does not occur instantaneously in the instrument and there is a finite time during which the RH is moving from one stable value to the next. During this period, the MC of the sample is not moving towards a static equilibrium point, which consequently affects the kinetics curve for the first minute. Nonlinear curve fitting with the function "expassoc" (Equation 1) was applied to analyse the adsorption and desorption data curves of the wood specimens (Origin 8.5 software, Origin Lab. Corporation, Northampton, MA, USA). Bespoke functions were developed for analysis of models with higher K-V series. As the first few points in this curve are associated with the sample MC under conditions of changing $\mathrm{RH}$, the characteristic times for any fit including these curves will not be representative of the material properties and they are consequently removed from the fit. However, as more points are excluded from the curve fitting process, the values for the mass changes for the fast and slow kinetics process become less accurate. In practice, with the data being collected every $20 \mathrm{~s}$, removal of the first three data points was sufficient to obtain good quality curve fits.

\section{Results and discussion}

\section{The applicability of the PEK model}

The procedure employed in curve fitting to the kinetic data has been discussed in considerable detail elsewhere (e.g.,
Hill et al. 2010a,b,c; Jalaludin et al. 2010c). The PEK model has been used extensively in studies of the sorption kinetics behaviour with many natural materials and provides extremely accurate fits to the sorption kinetics curves. Nonetheless, the fit in the present study is not exact (Figure 2), where a typical curve fit is presented along with the associated residuals in the plot below. This shows that there is a pattern in the residuals and that there are consequently terms missing from the kinetic equation. Kohler et al. (2003) did note this in their first paper, in which the sorption of plant fibres were studied by the PEK model and in which the effect of introducing a third term in the model was examined. The authors concluded that the addition of a third term did not result in any substantial improvement. Accordingly, the PEK model has been adopted in the literature for all subsequent studies. However, as can be seen from Figure 2, the introduction of a third kinetic term to the model does lead to a reduction in the residuals. Nonetheless, as shown in this example, a pattern in the residuals remains which could be possibly reduced by further terms. However, extensive analysis of these data and data from previous experiments has shown that this remaining pattern is an artefact caused by a slight regular variation in the data, which may be linked to a feedback issue with the DVS Intrinsic apparatus, possibly linked to a slight variation in the reservoir temperature. Attempts to improve fitting functions with four or five exponential terms did not further affect the residuals and it can be safely concluded that a three-term model is wholly adequate. On the other hand, extensive analysis of the kinetic data in this and 

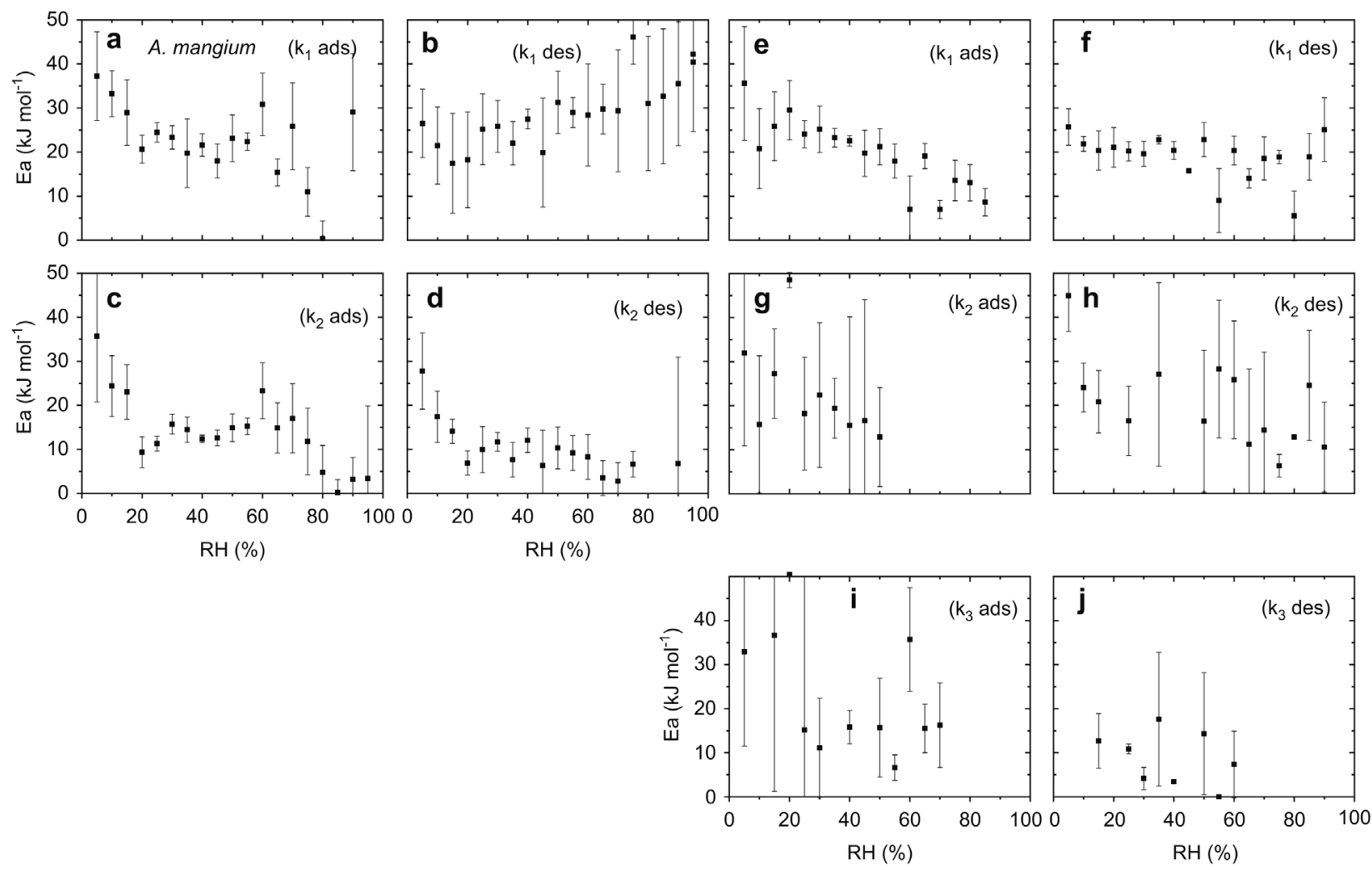

Figure 3 Variation in activation energy ( $E a)$ in 5\% RH steps over the hygroscopic range as derived from PEK fits (a-d) and TEK fits (e-j) to the sorption data of A. mangium. (a) Fast adsorption; (b) fast desorption; (c) slow adsorption; (d) slow desorption; (e) fast adsorption; (f) fast desorption; (g) medium adsorption; (h) medium desorption; (i) slow adsorption; (j) slow desorption.

the other studies performed previously have encountered problems when attempting to fit with the three term model; in that the fit does not always converge satisfactorily, despite choosing a wide range of starting values. In the following sections, the determination of activation energy, entropy, and Gibbs free energy is described and differences between the PEK and TEK analyses are compared. Other factors that affect the sorption kinetics curves (and hence the fitting parameters) are the RH step change and the sample mass. It is therefore imperative that for reliable sample to sample comparison that these two variables are controlled.

\section{Activation energy}

The variation in activation energy of sorption for different $\mathrm{RH}$ values is shown in Figure 3, for A. mangium (PEK adsorption $\mathrm{k}_{1}$ Figure $3 \mathrm{a}$, desorption $\mathrm{k}_{1}$ Figure $3 \mathrm{~b}$, adsorption $\mathrm{k}_{2}$ Figure $3 \mathrm{c}$, desorption $\mathrm{k}_{2}$ Figure $3 \mathrm{~d}$; TEK values are given in Figure $3 \mathrm{e}-\mathrm{j}$ ) and E. malaccense (PEK adsorption $\mathrm{k}_{1}$ Figure 4a, desorption $\mathrm{k}_{1}$ Figure 4b, adsorption $\mathrm{k}_{2}$ Figure 4c, desorption $\mathrm{k}_{2}$ Figure $4 \mathrm{~d}$; TEK values are given in Figure $4 \mathrm{e}-\mathrm{j}$ ). For clarity, the RH values reported in the plots are the programmed values and each step represents the final $\mathrm{RH}$ step in the adsorption mode and the initial $\mathrm{RH}$ value under desorption conditions (this convention is maintained throughout this paper). A number of observations can be made regarding the variation of activation energy of sorption throughout the hygroscopic range: a) With very few exceptions, the $E a$ is lower than 40 $\mathrm{kJ} \mathrm{mol}^{-1}$ and more typically between 10 and $30 \mathrm{~kJ} \mathrm{~mol}^{-}$ 1 . These values are consistent with hydrogen bond breaking/formation being associated with the rate determining step (Morrison and Dzieciuch 1959; McQueen-Mason and Cosgrove 1994; Markovitch and Agmon 2007). In a study of the swelling kinetics of wood in water Mantanis et al. (1994) reported values for the $E a$ of Sitka spruce and Scots pine as $32 \mathrm{~kJ} \mathrm{~mol}^{-1}$ and $48 \mathrm{~kJ} \mathrm{~mol}^{-1}$, respectively indicating that $\mathrm{H}$-bond breaking is the rate determining step in the swelling process. Passard and Perre (2005) applied a five K-V element model to creep data of spruce and oak, finding that the $E a$ associated with the fastest process was of the order of $60 \mathrm{~kJ} \mathrm{~mol}^{-1}$, but in excess of $100 \mathrm{~kJ} \mathrm{~mol}^{-1}$ for all of the other processes. However, such data cannot be compared with sorption or swelling because creep involves the imposition of an external stress and involves Maxwellian as well as $\mathrm{K}-\mathrm{V}$ elements. The much larger activation energies associated with creep are striking and may point to a fundamentally different mechanism for creep (i.e., microfibrillar shear processes) as recently discussed by Engelund and Svensson (2011).

b) There is no discernable pattern in the magnitude of Ea as the $\mathrm{RH}$ of the experiment (and hence the MC of the sample increases) with the possible exception of the behaviour illustrated in Figure 3d,e. A fall in Ea from 

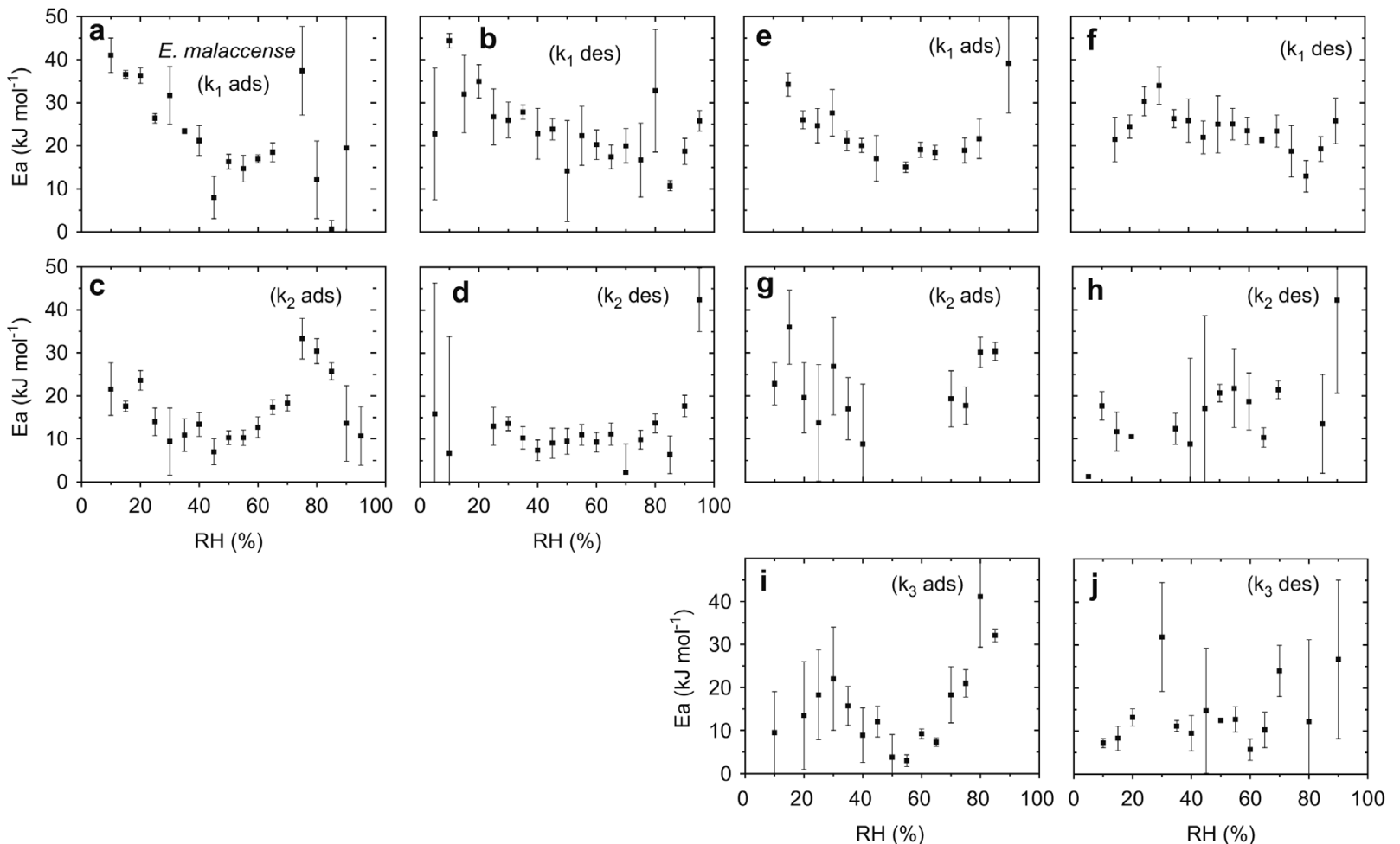

Figure 4 Variation in energy of activation ( $E a$ ) in 5\% RH steps over the hygroscopic range as derived from PEK fits (a-d) and TEK fits (e-j) to the sorption data of E. malaccense. (a) Fast adsorption; (b) fast desorption; (c) slow adsorption; (d) slow desorption; (e) fast adsorption; (f) fast desorption; (g) medium adsorption; (h) medium desorption; (i) slow adsorption; (j) slow desorption.

low RH to high RH values has been noted in previous studies with Sitka spruce (Hill et al. 2010b) and flax (Hill et al. 2010c). This was interpreted as H-bond breaking being related to the rate determining step at lower RH values, but that the amorphous matrix network became more open at higher $\mathrm{RH}$. The data presented here is less amenable to such a simple interpretation. Nonetheless, the values of $E a$ obtained are consistent with $\mathrm{H}$-bond breaking being the rate determining step.

c) There is considerable variation in the quality of the data, which is undoubtedly related to the narrow temperature range over which this study was undertaken. This is a limitation of this particular apparatus A minimum of five temperatures was used in an attempt to improve data quality, with the variable results seen here. However, although it is hard to discern any trends in the data, the $E a$ is nonetheless invariably lower than $40 \mathrm{~kJ} \mathrm{~mol}^{-1}$, giving confidence in the validity of the data set if not necessarily each individual data point. It is clear that introduction of the TEK model reduces the data quality of the activation energies related to $k_{2}$ and $k_{3}$, but does improve the quality of the $k_{1}$ data set.

\section{Entropy of activation}

Similar behaviour was found with respect to the sorption activation entropies (Figures 5 and 6) although an additional point can be made. The activation entropy is negative under conditions of both adsorption and desorption. Entropy change is related to the differences in the number of ways of distributing energy between an initial state and a final state. Under adsorption conditions, water vapour molecules lose a considerable amount of translational freedom when they move from a gaseous state to the highly confined environment of the cell wall nanopores. This would lead to a reduction of entropy for the water molecules. But the opposite occurs when the water molecules are desorbed out of the wood cell wall, yet the activation entropy remains negative. In order to understand why the activation entropy of both adsorption and desorption is negative, it is necessary to consider the nature of the rate determining step of the sorption processes. It has been previously argued in this paper that the ability of the material to deform controls the rate of sorption. This deformation is linked to the micro-Brownian motion of the macromolecular components of the cell wall. The activation entropy changes are therefore associated with these dynamic cell wall molecular processes. A reduction in entropy indicates that there is a loss of translational, rotational or vibrational degrees of freedom, or a combination of these, associated with the macromolecules in the rate determining step. The ingress or egress of water molecules into or out of the cell wall requires molecular rearrangements to take place to allow for expansion or collapse of the cell wall nanopores. Such rearrangements are facilitated by the presence of free volume in the immediate environment where local deformation takes place. However, in polymeric networks below the $T g$, where there is insufficient free-volume or where such motion is otherwise prevented by, e.g. cross- 

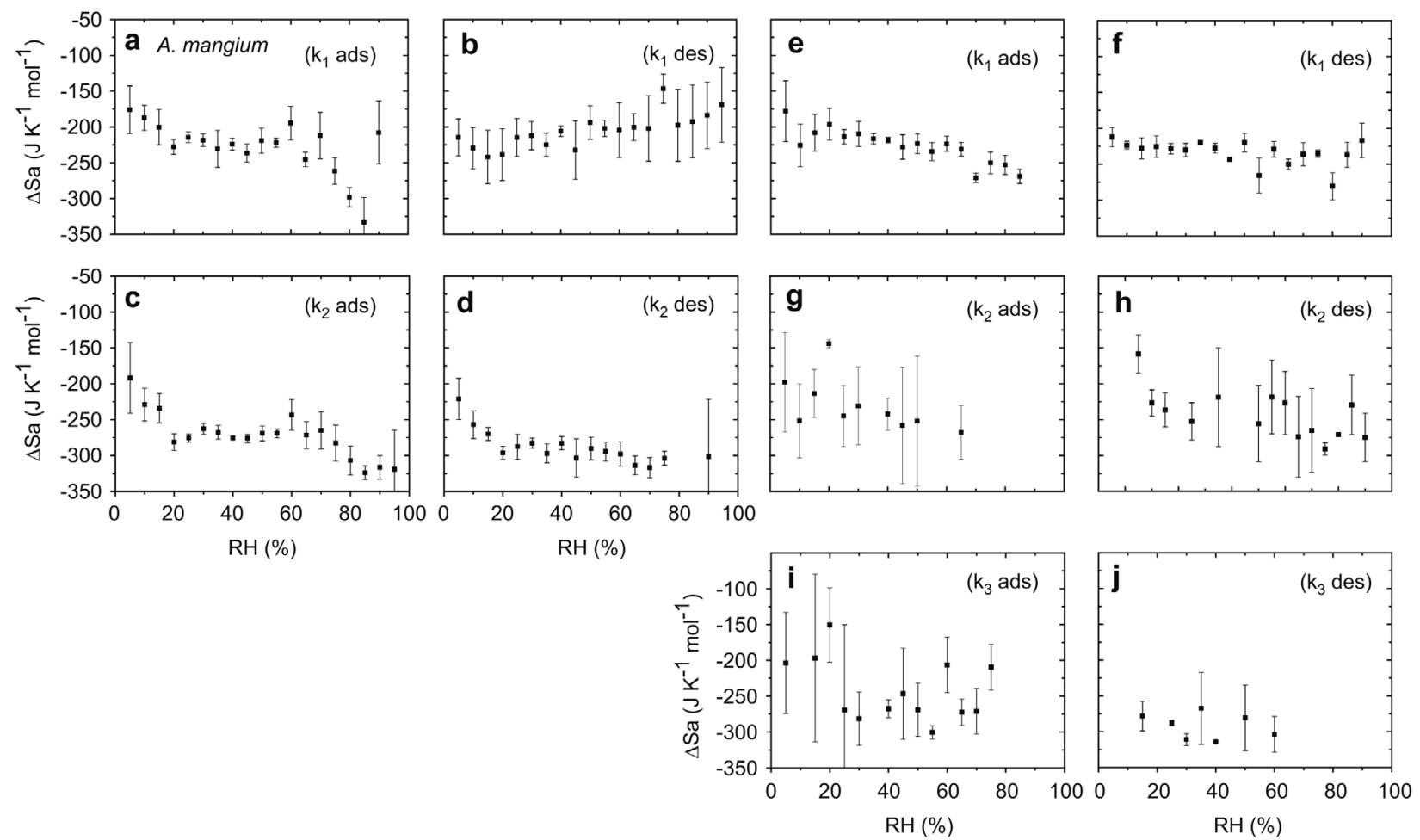

Figure 5 Variation in activation entropy $(\triangle \mathrm{Sa})$ in $5 \% \mathrm{RH}$ steps over the hygroscopic range as derived from PEK fits (a-d) and TEK fits (e-j) to the sorption data of A. mangium. (a) Fast adsorption; (b) fast desorption; (c) slow adsorption; (d) slow desorption; (e) fast adsorption; (f) fast desorption; (g) medium adsorption; (h) medium desorption; (i) slow adsorption; (j) slow desorption.
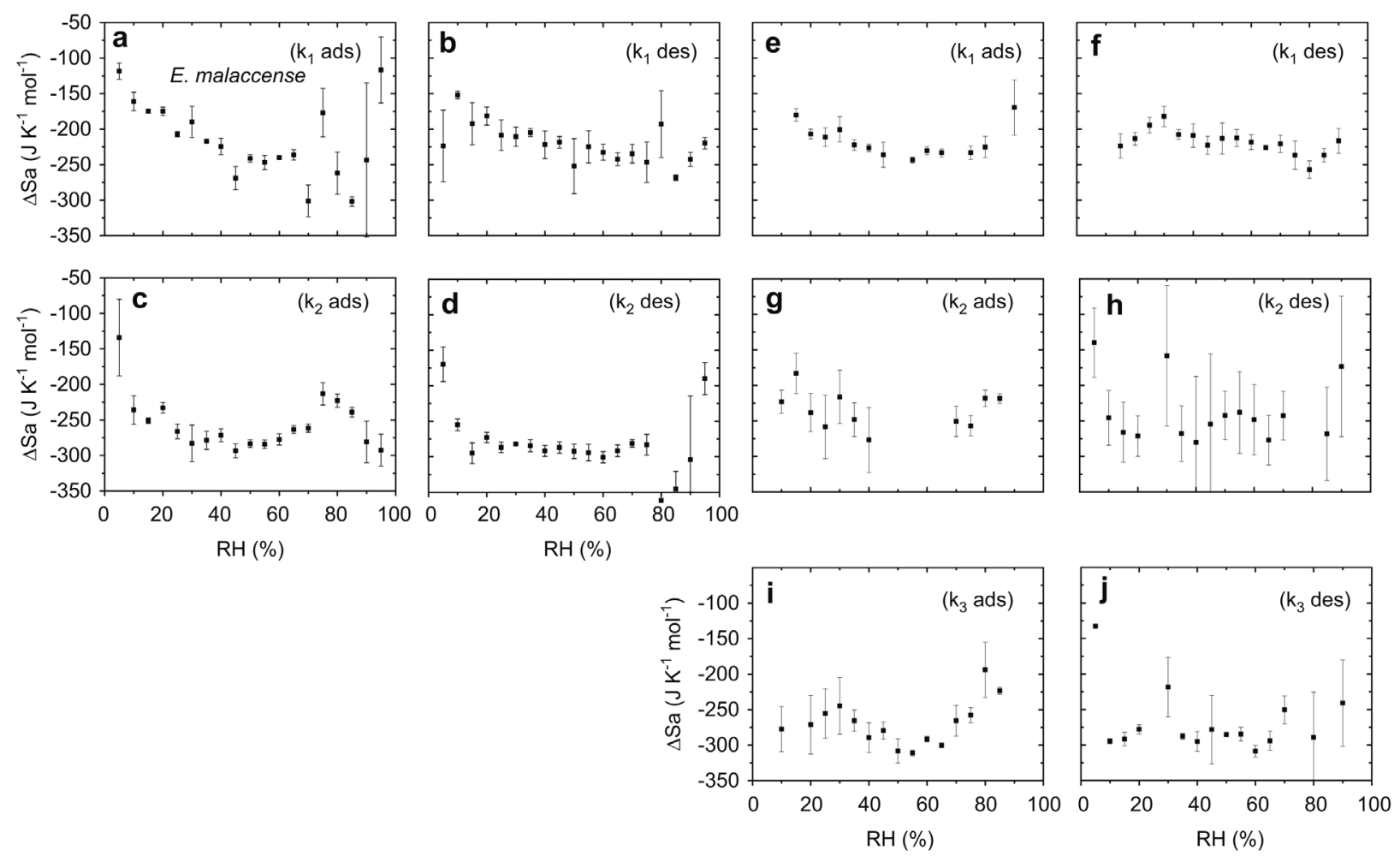

Figure 6 Variation in entropy of activation $(\triangle \mathrm{Sa})$ in 5\% RH steps over the hygroscopic range as derived from PEK fits (a-d) and TEK fits (e-j) to the sorption data of E. malaccense. (a) Fast adsorption; (b) fast desorption; (c) slow adsorption; (d) slow desorption; (e) fast adsorption; (f) fast desorption; (g) medium adsorption; (h) medium desorption; (i) slow adsorption; (j) slow desorption. 

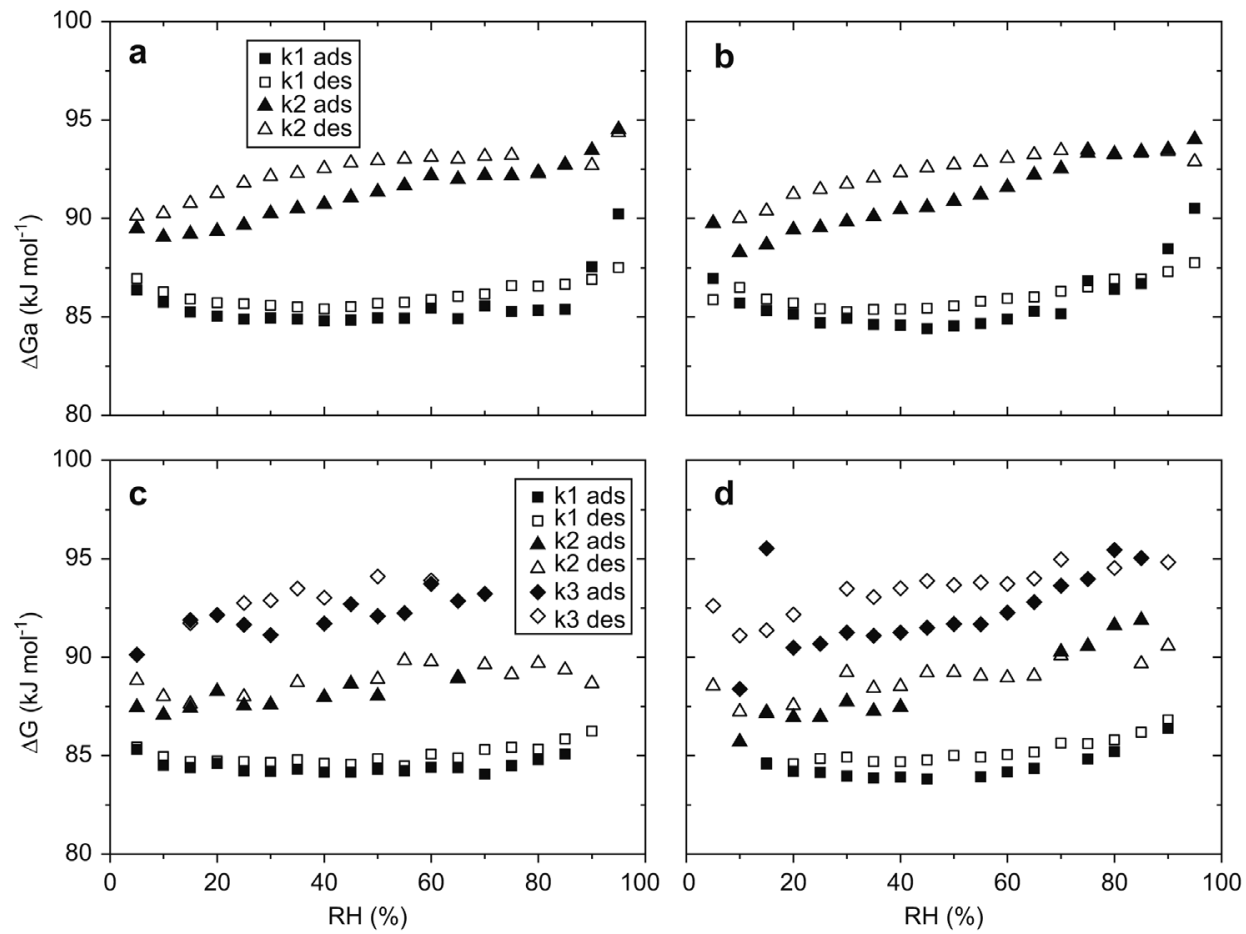

Figure 7 Variation in the Gibbs free energy of activation $(\Delta G a)$ in $5 \%$ RH steps over the hygroscopic range for A. mangium (a) and E. malaccense (b) as derived from PEK analysis of the sorption kinetics data. The differences in Gibbs free energy of activation calculated using TEK fitting parameters to the same kinetic data are shown for A. mangium (c) and E. malaccense (d).

linking, then the local deformation requires cooperative motion over a more extensive region of the polymeric network (Matsuoka 1992; Matsuoka and Hale 1997; Bartolotta et al. 2010). This non-random cooperative motion results in a negative activation entropy.

\section{Gibbs free energy of activation}

Changes in the Gibbs free energy of activation at different $\mathrm{RH}$ values are given in Figure 7 for A. mangium (Figure $7 \mathrm{a}, \mathrm{c}$ ) and E. malaccense (Figure 7b,d). Referring first to the Gibbs free energy data obtained based on PEK analysis (Figure 7a,b). The variation in the $\Delta G a$ values shows some clear trends with both of the wood species in this study. There are obvious differences between the adsorption and desorption $\Delta G a$ values for both the fast and slow processes. The following observations can be made with reference to the data of Figure 7:

(a) Apart from at the highest and lowest ends of the hygroscopic range, the $\Delta G a$ values of adsorption are usually lower than those of desorption;

(b) $\Delta G a$ values are always positive;

(c) $\Delta G a$ values for the fast process are always greater than those associated with the slow process;

(d) The trend in $\Delta G a$ is upwards with increasing $\mathrm{RH}$ for the slow processes reaching a maximum value at about $60-70 \% \mathrm{RH}$ for the fast process under desorption. With the fast process, the trend in $\Delta G a$ is downwards from 5 to $30 \% \mathrm{RH}$ and then begins to increase.
It has been stated that, at least where kinetic studies involving enzymes are concerned, that the use of $E a$ in the determination of reaction mechanisms is inappropriate unless it is known that the entropic term is constant (Low et al. 1973). It has been clearly demonstrated herein that the entropy of activation varies at different $\mathrm{RH}$ values, indicating that a complete interpretation of the sorption kinetics based on activation energies alone is not possible.

The suggestion made in this paper is that the sorption kinetics behaviour is controlled by the ability of the cell wall polymer network to deform in the dynamic environment where water molecules are travelling through the inter-microfibrillar matrix. It is considered that hydrogen bond breaking or formation plays a part in this process and that evidence for this may be found in the values obtained for the activation energies. However, there are also matrix polymer deformation processes that contribute towards the entropic component in the rate determining step. The overall process is therefore only fully represented by examination of the Gibbs free energy of activation, which has contributions from both enthalpic (activation energy) and entropic terms. The reason why $\Delta G a$ for the slow process increases and then declines as RH increases is not, at present, clear. The initial reduction in $\Delta G a$ with cell wall MC can be rationalised as being related to the plasticisation of the cell wall matrix polymers by water as cell wall MC increases, but this interpretation cannot be generalised because this behaviour is not always observed. There is no simple explanation for the subsequent increase in $\Delta G a$ at higher $\mathrm{RH}$ contents. The differ- 

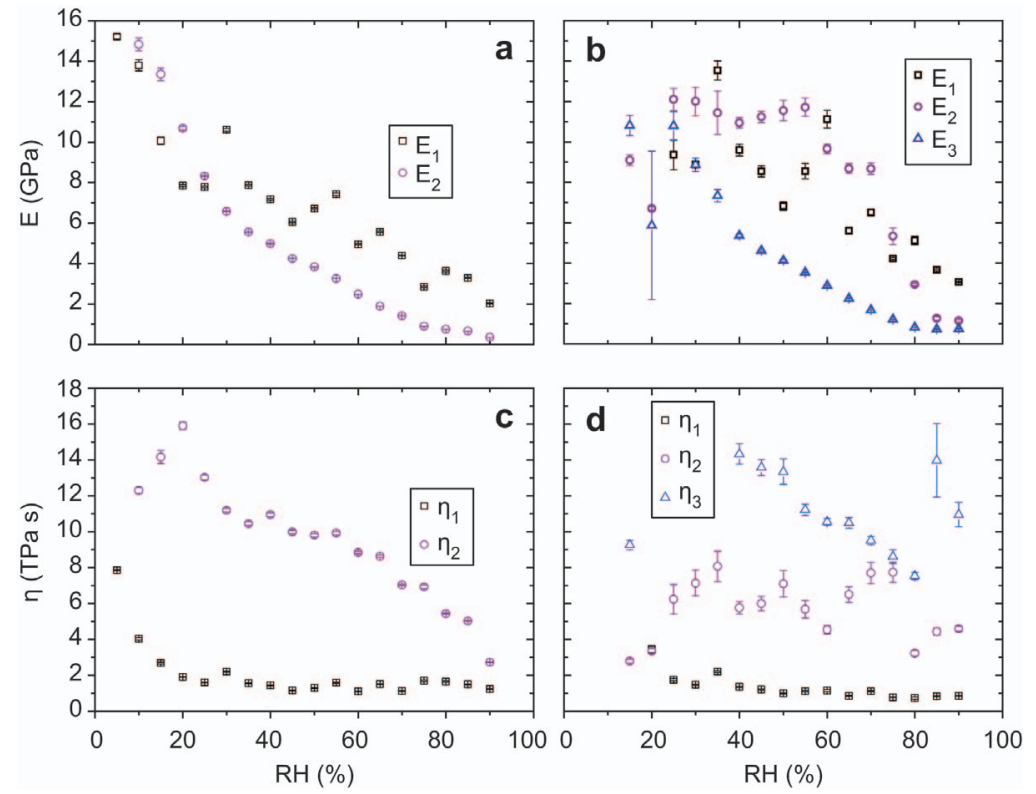

Figure 8 Comparison between the cell wall internal moduli and viscosities as determined from the Kelvin-Voigt interpretation of the sorption kinetics data from the PEK $(a, c)$ and TEK $(b, d)$ model fits. Example given here is for E. malaccense.

ences in behaviour of $\Delta G a$ between the fast and slow processes are also at the present time not understood.

\section{Interpretation of sorption kinetics based on the Kelvin-Voigt model}

The sorption kinetic parameters were used as input into Equation 6, with the swelling pressure associated with each measured RH incremental step calculated according to Equation 7. Results were determined for the fast and slow processes at each temperature and for both wood species, although only data set for one wood species at one temperature is shown in this paper. The variation in matrix modulus related to the slow kinetic process $\left(E_{1}\right)$ and fast kinetic process $\left(E_{2}\right)$ is presented in Figure 8 for $E$. malaccense at a temperature of $20^{\circ} \mathrm{C}$. Values for the modulus at low cell wall $\mathrm{MC}$ are generally of the order of $10 \mathrm{GPa}$ to $15 \mathrm{GPa}$.

There is no publication, in which the cell wall modulus has been determined by the application of an internal stress, as is occurring with these sorption experiments (it is not clear how such an experiment could be performed). However, the calculated values appear to be reasonable given that Salmén (2001) reports the modulus of dry hemicellulose as $2 \mathrm{GPa}$ (reducing to $40 \mathrm{MPa}$ at high $\mathrm{MC}$ ) and that for dry lignin as $2 \mathrm{GPa}$; an off-axis modulus of $20 \mathrm{GPa}$ is quoted for the microfibril. Nanoindentation methods have given values for the modulus of the order 13 to $21 \mathrm{GPa}$ for the cell wall of spruce (Wimmer et al. 1997; Gindl and Gupta 2002; Gindl and Schöberl 2004). Although there is some scatter in the values in the graphs, it is clear that there is a decrease in modulus as RH increases. The magnitudes of $E_{2}$ also exhibit a range of values that appear reasonable. As with $E_{1}$, the $E_{2}$ modulus decreases to very low values at the upper end of the hygroscopic range. This applies irrespective of whether the PEK (Figure 8a) or TEK (Figure 8b) analytical models are applied. Although a decrease in modulus with increasing cell wall MC is a well-known phenomenon, such low values as seen here are not observed when external stresses are applied.

It is not possible to verify whether the viscosity values calculated obtained by this method are correct. Literature determinations of such properties are relying on dynamic mechanical measurements and it is not possible to correlate such data with the results obtained here. However, there is one study of the creep behaviour of macroscopic spruce samples quoting viscosity values as high as $10^{13}-10^{14} \mathrm{~Pa} \mathrm{~s}$ (Lagaňa et al. 2008), which is one to two orders of magnitude higher than the values calculated from the sorption kinetics data. However, the type of behaviour is quite different, as external applied stress and creep effects are absent in the sorption experiments. There was no difference noted between the two wood species in this study for the evaluated results for matrix modulus and viscosity.

With the PEK model it was only with the $E_{2}$ modulus and the $\eta_{2}$ viscosity where differences were noted between values for adsorption and desorption (Figure 9a,c,e and g). This can be interpreted that the hysteresis phenomenon is only associated with the slow sorption process (with the TEK model, this applies only to the slowest relaxation process) (Figure 9b,d,f,h,i and j). The question then arises as to what the two processes represent physically? The occurrence of dual relaxation processes is a commonly reported phenomenon in the polymer scientific literature where bi-component systems are studied (Spontak and Vratsanos 2000). The obvious interpretation in terms of wood is perhaps that the two relaxation processes are associated with crystalline (cellulosic) and the amorphous (hemicellulosic and lignin) components of the cell wall matrix (Nakao and Nakano 2011). In the case of the TEK model, it may perhaps be possible to 

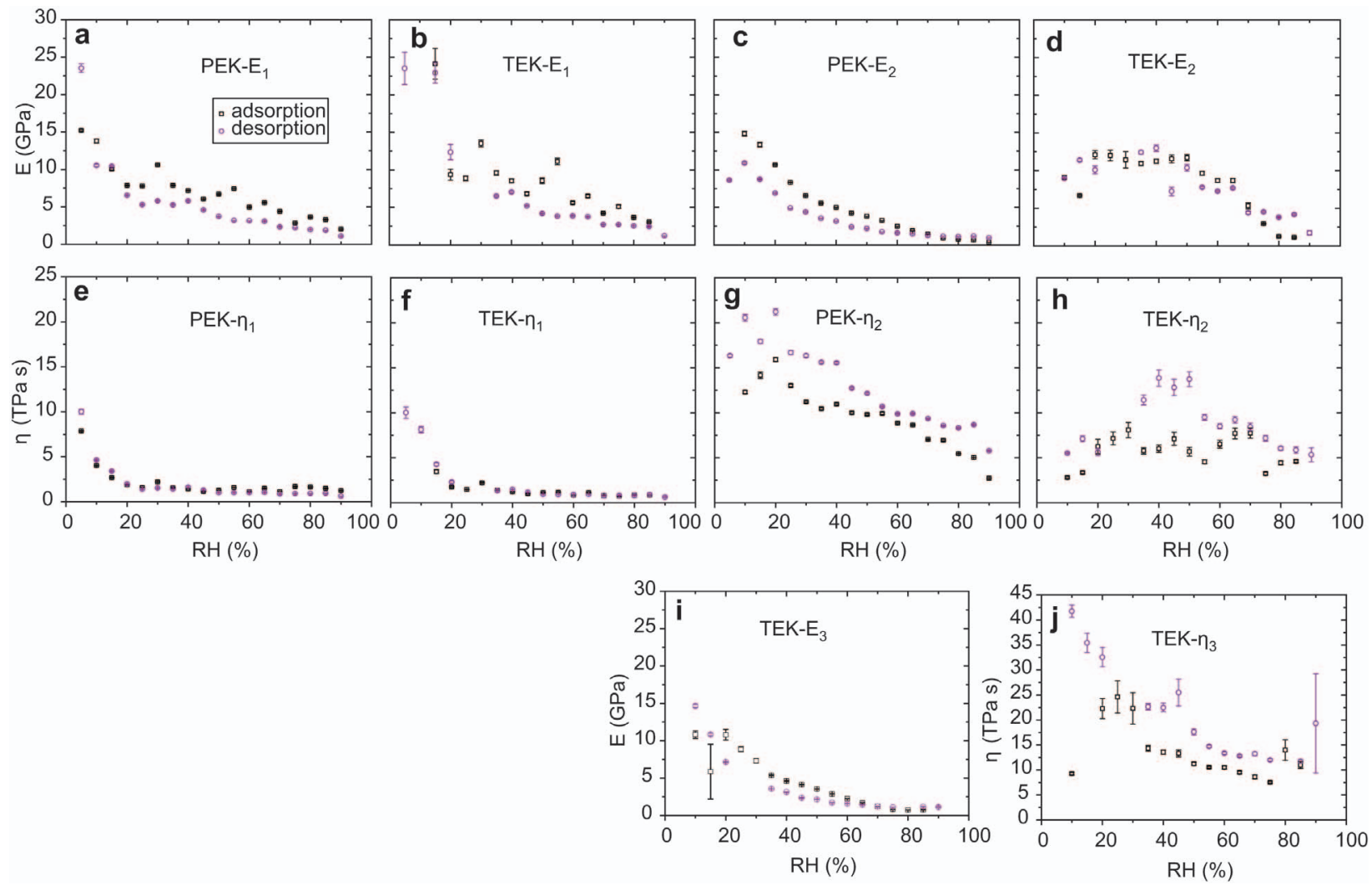

Figure 9 Differences in moduli for the fast (a) and slow (c) sorption processes and fast (e) and slow (g) viscosities as determined by Kelvin-Voigt interpretation of the PEK sorption data. The same plots based on the TEK sorption data are fast process modulus (b) medium rate process modulus (d), slow rate modulus (i). The TEK viscosities for fast rate, medium rate and slow process rate are shown in graphs $\mathrm{f}, \mathrm{h}$, and $\mathrm{j}$, respectively. Example given here is for E. malaccense.

assign the three components to cellulose, hemicellulose and lignin. It is clear that further work is needed in order to examine whether this tentative hypothesis has any validity.

\section{Is there connection between sorption kinetics and hysteresis?}

In studies of the hysteresis phenomenon in isotherms associated with humic soils, Lu and Pignatello (2002, 2004) also considered the importance of matrix stiffness in glassy solids. The glassy state is specified as a material possessing molecular-scale nanopores embedded in a matrix which is unable to fully relax to a thermodynamic equilibrium state due to the stiffness of the matrix macromolecules. The glassy state is favoured by matrix crosslinking which reduces the mobility of the macromolecules; this being a characteristic of humic substances in soils and lignin in the wood cell wall. They noted that the process of adsorption in glassy solids results in the creation and enlargement of nanopores and that this process is inelastic on the time scale of molecular diffusion. During adsorption, the thermal motion of the incoming water molecules induces the opening of the nanopores, resulting in the creation of new internal surface. During desorption, there is a time lag between the water molecules going out of the nanopores and the rearrangement of the enveloping matrix to its equilibrium configuration. The establishment of this thermodynamically stable configuration is therefore kinetically hindered under conditions of adsorption and desorption. This means that adsorption and desorption take place in different physical environments. This behaviour relates to a glassy material that is below the glass transition temperature $(T g)$. As the isotherm temperature increases and $T g$ is approached, the size of the hysteresis loop decreases and becomes zero at $T g$ (Hill et al. 2009). This is because at $T g$ the matrix responds to the ingress or egress of water molecules essentially instantaneously. The time scales involved in these molecular processes are of the order of $10^{-10} \mathrm{~s}$, yet differences in the time constants of the slow kinetic process are of the order of minutes. How then can these two very different time scales be reconciled?

Below the $T g$, matrix relaxation relies upon cooperative motion between neighbouring molecules because there is insufficient free volume surrounding each of the relaxing molecules (relaxors) to allow relaxation in isolation. The rate of relaxation therefore depends upon the energy barrier associated with the relaxation process and the degree of cooperation. Domains of cooperation are thus formed whose size is determined by the number of collaborative relaxors required to allow relaxation to take place. The lower the temperature, at which these processes take place, the larger 
is the required domain size. The relaxation time increases with the domain size $(1 / \mathrm{n}$-th power, where $n$ is the number of cooperative relaxors) and the observed relaxation times depend upon the domain population distribution with larger domains being predominant (Matsuoka 1992). Matsuoka (1992) shows that relaxation times of the order of minutes will be commonly observed even though individual relaxations occur on the timescale of $10^{-10} \mathrm{~s}$ at room temperature.

The macroscopic timescales determined in the sorption kinetic experiments can be linked to the molecular behaviour. Therefore, it seems to be possible to examine the hysteresis phenomenon through sorption kinetics experiments. This line of research is now being actively pursued in our laboratories.

\section{Conclusions}

By analysing data of water vapour sorption according to the parallel exponential kinetics (PEK) model, it has been possible to obtain values for the activation energy, entropy, and Gibbs free energy of sorption throughout the hygroscopic range. The trend in behaviour of the activation energy $(E a)$ with $\mathrm{RH}$ has given mixed results. Activation energies above $40 \mathrm{~kJ} \mathrm{~mol}^{-1}$ are seldom observed and they are more typically $30 \mathrm{~kJ} \mathrm{~mol}^{-1}$ or lower, magnitudes entirely consistent with the rate limiting step being associated with $\mathrm{H}$-bond breaking or formation. Values for activation entropy are always negative for both adsorption and desorption processes. This is interpreted as being due to the rate determining step for dynamic sorption processes being associated with molecular rearrangements within the cell wall matrix. Macromolecular relaxation in the matrix to allow for the transport of water molecules requires cooperative behaviour between adjacent molecules when the isotherm is performed below the $T g$ of the substrate. Such cooperative behaviour is responsible for the negative entropy of activation. Evaluation of the Gibbs free energy of activation $(\Delta G a)$ reveals some very clear trends in behaviour as RH is increased. The $\Delta G a$ values for the slow process are higher than those associated with the fast sorption process. Similarly $\Delta G a$ values for desorption are invariably higher than those for adsorption except at the higher end of the hygroscopic range. Whilst $\Delta G a$ for the fast process initially decreases and then increases as $\mathrm{RH}$ rises, the $\Delta G a$ values for the slow process increase throughout the hygroscopic range. The reasons for this behaviour with respect to $\Delta G a$ are not understood at the present time. It is, however, clear that a full understanding requires the determination of entropy and Gibbs free energy of activation as well as activation energy. Analysis of the residuals from the curve fitting process has revealed that an improved fit is obtained from a three-term model, rather than the two-term PEK model commonly adopted. However, although the fit is improved, in practice, it becomes much more difficult to get a fit to converge to the data points and the errors associated with the characteristic times are larger for the slower processes. When TEK parameters are used to calculate the activation energy, entropy and Gibbs free energy, the same broad conclusions can be drawn: the activation energy is of the order of a H-bond, the activation entropy is negative, and the Gibbs free energy increases with slower kinetic processes. When the data from the parallel exponential kinetics analyses of sorption kinetics experiments are evaluated based on a Kelvin-Voigt viscoelastic model, it is possible to obtain values for cell wall matrix modulus and viscosity. Both modulus and viscosity decrease with increasing relative humidity (and hence cell wall MC) but only the viscosity associated with the slow sorption process shows any dependency upon temperature. Only the modulus and viscosity associated with the slowest sorption process show any difference between adsorption and desorption. Thus, a link with hysteresis may be found only in the slow sorption process. Finally, it is suggested how hysteresis, which is linked to molecular dynamics occurring in time scales of the order of picoseconds, can be linked to sorption kinetics phenomena, which have time constants of the order of minutes. The connection lies with consideration of the nature of cooperative relaxations that have to occur in glassy materials below the $T g$ when subjected to an internal stress.

\section{Acknowledgements}

Callum Hill wishes to thank the Scottish Funding Council for funding under the auspices of the Joint Research Institute for Civil and Environmental Engineering of the Edinburgh Research Partnership. Zaihan Jalaludin is grateful to the Ministry of Natural Resources and Environment Malaysia for a study scholarship. Eike Mahrdt expresses his thanks to the European Commission for an internship at Edinburgh Napier University funded by the Leonardo Da Vinci Programme. Barbara Keating acknowledges support from the Daphne Jackson Trust.

\section{References}

Alfrey, T., Gurnee, E.F., Lloyd, W.G. (1966) Diffusion in glassy polymers. J. Polym. Sci. C12:2837-2844.

Barnes, H.A., Hutton, J.F., Walters, K. (1989) An Introduction to Rheology. Elsevier, Amsterdam, The Netherlands.

Bartolotta, A., Carini, G., Carini, G., Di Marco, G., Tripodo, G. (2010) Subglass cooperative mechanical relaxations and activation entropy in heterocyclic polymeric networks. Macromolecules 43:4798-4804.

Christensen, G.N. (1959) The rate of sorption by wood and pulp. Appita 13:112-123.

Christensen, G.N. (1965) The rate of sorption of water vapour by thin materials. Humidity Moisture 4:279-293.

Crank, J. (1998) The Mathematics of Diffusion, 2nd edition. Oxford Science Publications, Oxford, UK.

Dieste, A., Krause, A., Militz, H. (2008) Modification of Fagus sylvatica (L.) with 1,3-dimethylol-4,5-dihydroxyethylene urea (DMDHEU): Part 1. Estimation of heat adsorption by the isosteric method (Hailwood-Horrobin model) and by solution calorimetry. Holzforschung 62:577-583.

Droin, A., Taverdet, J.L., Vergnaud, J.M. (1988) Modelling the kinetics of moisture adsorption by wood. Wood Sci. Technol. 22:11-20.

Engelund, E.T., Svensson, S. (2011) Modelling time-dependent mechanical behaviour of softwood using deformation kinetics. Holzforschung 65:231-237. 
Gindl, W., Gupta, H.S. (2002) Cell wall hardness and Young's modulus of melamine-modified spruce wood by nanoindentation. Composites Part A 33:1141-1145.

Gindl, W., Schöberl, T. (2004) The significance of the elastic modulus of wood cell walls obtained by nanoindentation measurements. Composites Part A 35:1245-1349.

Glasstone, S., Lewis, D. (1960). Elements of Physical Chemistry. Macmillan, London.

Herritsch, A., Nijdam, J.J. (2009) An improved drying model for highly-impermeable hardwoods. Holzforschung 63:464-471.

Hill, C.A.S., Papadopoulos, A.N. (2002). The pyridine-catalysed acylation of pine sapwood and phenolic model compounds with carboxylic acid anhydrides. Determination of activation energies and entropy of activation. Holzforschung 56:150-156.

Hill, C.A.S., Xie, Y. (2011a) The dynamic water vapour sorption properties of natural fibres and viscoelastic behaviour of the cell wall - is there a link between sorption kinetics and hysteresis? J. Mat. Sci. 46:3738-3748.

Hill, C.A.S., Norton, A., Newman, G. (2009) The water vapor sorption behavior of natural fibers. J. Appl. Polym. Sci. 112:15241537.

Hill, C.A.S., Norton, A., Newman, G. (2010a) Analysis of the water vapour sorption behaviour of Sitka spruce (Picea sitchensis (Bongard) Carr.) based on the parallel exponential kinetics model. Holzforschung 64:469-473.

Hill, C.A.S., Norton, A., Newman, G. (2010b) The water vapour sorption properties of Sitka spruce determined using a dynamic vapour sorption apparatus. Wood Sci. Technol. 44:497-514.

Hill, C.A.S., Norton, A., Newman, G. (2010c) The water vapour sorption behaviour of flax fibers - analysis using the parallel exponential kinetics model and determination of the activation energies of sorption. J. Appl. Polym. Sci. 116:2166-2173.

Hill, C.A.S., Moore, J., Jalaludin, Z., Leveneu, M., Mahrdt, E. (2011) The Influence of earlywood/latewood and ring position upon the water vapour sorption properties of Sitka spruce. Int. Wood Prod. J. (accepted).

Houska, M., Koc, P. (2000) Sorptive stress estimation: an important key to the mechano-sorptive effect in wood. Mech. Time Depend. Mat. 4:81-98.

Jalaludin, Z., Hill, C.A.S., Curling, S., Hashim, W.S., Hamdam, H. (2010a) The kinetics of water vapour sorption: analysis using the parallel exponential kinetics model on six Malaysian tropical hardwoods. J. Trop. For. Sci. 22:107-117.

Jalaludin, Z., Hill, C.A.S., Curling, S.F., Xie, Y., Samsi, H.W., Hussein, H. (2010b) Analysis of the water vapour sorption isotherms of thermally modified acacia and sesendok. Wood Mat. Sci. Eng. 5:194-203.

Jalaludin, Z., Hill, C.A.S., Samsi, H.W., Husain, H., Xie, Y. (2010c) The kinetics of water vapour sorption: analysis using the parallel exponential kinetics model on Acacia (Acacia mangium) and Sesendok (Endospermum malaccense) oleo-thermal modified wood. Holzforschung 64:763-770.

Kachrimanis, K., Noisternig, M.F., Griesser, U.J., Malamataris, S. (2006) Dynamic moisture sorption and desorption of standard and silicified microcrystalline cellulose. Eur. J. Pharm. Biopharm. 64:307-315.

Kohler, R., Renate, D., Bernhard, A., Rainer, A. (2003) A numeric model for the kinetics of water vapour sorption on cellulosic reinforcement fibers. Compos. Interfaces 10:255-257.

Krabbenhoft, K., Damkilde, L. (2004) A model for non-Fickian moisture transfer in wood. Matérieux Constructions 37:615-622.

Lagaňa, R., Babiak, M., Krakovsky, A. (2008) Creep parameters of spruce wood in high temperature environment. Maderas: Ciencia y Tecnologia 10:19-24.
Low, P.S., Bada, J.L., Somero, G.N. (1973) Temperature adaptation of enzymes: roles of the free energy, the enthalpy, and the entropy of activation. Proc. Natl. Acad. Sci. 70:430-432.

Lu, Y., Pignatello, J.J. (2002) Demonstration of the "conditioning effect' in soil organic matter in support of a pore deformation mechanism for sorption hysteresis. Environ. Sci. Technol. 36: 4553-4561.

Lu, Y., Pignatello, J.J. (2004) History-dependent sorption in humic acids and a lignite in the context of a polymer model for natural organic matter. Environ. Sci. Technol. 38:5853-5862.

Madamba, P.S., Driscol, R.H., Buckle, K.A.J. (1996) The thin layer drying characteristics of garlic slices. Food Eng. 29:75-97.

Mantanis, G.I., Young, R.A., Rowell, R.M. (1994) Swelling of wood. Part 1. Swelling in water. Wood Sci. Technol. 28:119134.

Markovitch, O., Agmon, N. (2007) Structure and energetics of the hydronium hydration shells. J. Phys. Chem. Letts. 111:22532256.

Matsuoka, S. (1992) Relaxation Phenomena in Polymers. Hanser, New York.

Matsuoka, S., Hale, A. (1997) Cooperative relaxation processes in polymers. J. Appl. Polym. Sci. 64:77-93.

McQueen-Mason, S., Cosgrove, D.J. (1994) Disruption of hydrogen bonding between plant cell wall polymers by proteins that induce cell wall extension. Proc. Natl. Acad. Sci. USA 91: 6574-6578.

Morrison, J.L., Dzieciuch, M.A. (1959) The thermodynamic properties of the system cellulose-water vapor. Can. J. Chem. 37: 1379-1390.

Nakao, S., Nakano, T. (2011) Analysis of molecular dynamics of moist wood components by applying the stretched-exponential function. J. Mater. Sci. Doi 10.1007/s10853-011-5385-z.

Okubayashi, S., Griesser, U.J., Bechtold, T. (2004) A kinetic study of moisture sorption and desorption on lyocell fibers. Carbohyd. Polym. 58:293-299.

Okubayashi, S., Griesser, U.J., Bechtold, T. (2005a) Moisture sorption/desorption behavior of various manmade cellulosic fibers. J. Appl. Polym. Sci. 97:1621-1625.

Okubayashi, S., Griesser, U.J., Bechtold, T. (2005b) Water accessibilities of man-made cellulosic fibers - effects of fiber characteristics. Cellulose 12:403-410.

Passard, J., Perre, P. (2005) Viscoelastic behaviour of green wood across the grain. Part 2. A temperature dependent constitutive model defined by inverse method. Ann. For. Sci., 62:823-830.

Pfriem, A., Zauer, M., Wagenführ, A. (2010) Alteration of the unsteady sorption behaviour of maple (Acer pseudoplatanus L.) and spruce (Picea abies (L.) Karst.) due to thermal modification. Holzforschung 64:235-241.

Rahman, M.S., Perera, C.O., Thebaud, C. (1998) Desorption isotherm and heat pump drying kinetics of peas. Food Res. Int. 30:485-491.

Salin, J.-G. (2010) Problems and solutions in wood drying modelling: history and future. Wood Mat. Sci. Eng. 5:123-134.

Salmén, L. (2001) Micromechanics of the wood cell wall: a tool for the better understanding of its structure. In: Proceedings of the $1^{\text {st }}$ International Conference of the European Society for Wood Mechanics. Ed. Navi, P. EFPL, Lausanne, Switzerland, pp. 385-398.

Sharratt, V., Hill, C.A.S., Jalaludin, Z., Kint, D.P.R. (2010) Photodegradation and weathering effects on timber surface moisture profiles as studied using dynamic vapour sorption. Polym. Degr. Stab. 95:2659-2662.

Shi, S.Q. (2007) Diffusion model based on Fick's second law for 
the moisture adsorption processes in wood fibre-based composites: is it suitable or not? Wood Sci. Technol. 41:645-658.

Siau, J.F. (1984) Transport processes in wood. Springer-Verlag, Berlin.

Simpson, W. (1980) Sorption theories applied to wood. Wood Fiber 12:183-195.

Skaar, C. (1988) Wood-water relationship. Springer-Verlag, Berlin.

Spontak, R.J., Vratsanos, M.S. (2000) Stress relaxation activation in rubber-modified polymer systems exhibiting controlled miscibility through blending. Macromolecules 33:2290-2292.

Tang, X., De Rooij, M.R., Van Duynhoven, J., Van Breugel, K. (2008) Dynamic volume change measurements of cereal materials by environmental scanning microscopy and videomicroscopy. J. Microsc. 230:100-107.

Time, B. (2002) Studies on hygroscopic moisture transport in Norway spruce (Picea abies) Part 2: modelling of transient moisture transport and hysteresis in wood. Holz Roh Werk. 60:405-410.

Todoruk, T.M., Hartley, I.D. (2011) Sorption isotherm of lodgepole pine (Pinus contorta Dougl. Ex Loud.) pulp chips affected by the mountain pine beetle (Dendroctonus ponderosae). Holzforschung 65:109-112.

Venkateswaram, A. (1970) Sorption of aqueous and nonaqueous media by wood and cellulose. Chem. Revs. 70:619-637.

Wadsö, L. (1994a) Unsteady-state water vapor adsorption in wood: an experimental study. Wood Fiber Sci. 26:36-50.
Wadsö, L. (1994b) Describing non-Fickian water-vapour sorption in wood. J. Mat Sci. 29:2367-2372.

Wimmer, R., Lucas, B.N., Tsui, T.Y., Oliver, W.C. (1997) Longitudinal hardness and Young's modulus of spruce tracheid secondary walls using nanoindentation technique. Wood Sci. Technol. 31:131-141.

Xie, Y., Hill, C., Xiao, Z., Jalaludin, Z., Militz, H., Mai, C. (2010a) The water vapour sorption kinetics of wood modified with glutaraldehyde. J. Appl. Polym. Sci. 117:1674-1682.

Xie, Y., Hill, C.A.S., Xiao, Z., Mai, C., Militz, H. (2011a) Dynamic water vapour sorption properties of wood treated with glutaraldehyde. Wood Sci. Technol. 45:49-61.

Xie, Y., Hill, C.A.S., Jalaludin, Z., Curling, S.F., Ananjiwala, R.D., Norton, A., Newman, G. (2010b) The dynamic water vapour sorption behaviour of natural fibres and kinetic analysis using the parallel exponential kinetics model. J. Mat. Sci. 46:479-489.

Xie, Y., Hill, C.A.S., Jalaludin, Z., Sun, D. (2011b) The water vapour sorption behaviour of three celluloses: analysis using parallel exponential kinetics and interpretation using the KelvinVoigt viscoelastic model. Cellulose 18:517-530.

Received October 12, 2010. Accepted June 1, 2011.

Previously published online July 8, 2011. 